\title{
The Morphology of Inhabited Villages based on Hui Psychological Traits
}

\author{
Ningna Yan ${ }^{1,2}$ \\ 1 School of Architecture in Xi'an University of \\ Architecture and Technology, Xi'an,China \\ 2 Institute Civil Engineering And Water Conservancy in \\ Ningxia University, Yinchuan,China \\ E-mail: ynnandzzw@sina.com
}

\author{
Ke Feng \\ School of Architecture in Tianjin University, \\ Tianjin, China \\ E-mail: fengke327@163.com
}

\begin{abstract}
The main object of this fundamental research will be to reveal the relationship between Muslim group consciousness and settlement patterns. The method used in our study is known as field survey and literature research. The study showed that the morphological of Inhabited decided by Hui psychological traits.” Form our research work, we concluded that "Living around the mosque" is the most important feature of the "Hui Fang". "Hui Fang" and the sense of belonging have many deep relationships. The research has also explored that psychological characteristics in shape under the influence of factors showing the regularity and characteristics, in order to provide strategic Hui rural settlement construction.
\end{abstract}

Keywords-hui psychological traits; sense of community; sense of belonging

\section{INTRODUCTION}

Mental characteristics of Hui is the formation of the Hui nationality in the process of formation and development of distinctive personalities, emotions, tastes, customs ethos of total, while penetration of Hui nationality's common cultural traditions, national consciousness, national sentiment and national character, determining the national personality and behavior pattern of common psychological and spiritual structure. Development and progress of the Hui nationality, mental characteristics play an important or even decisive role, national psychological characteristics determine the behaviour of people [1], which the group consciousness of the Hui nationality, a sense of belonging, such as psychological trait determines the Hui in China wither placed his own way.

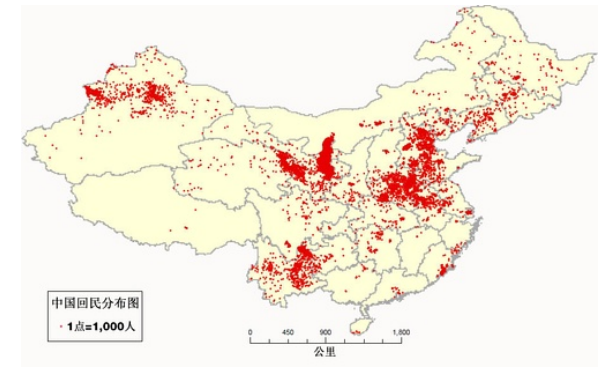

FIGURE I. CHINESE HUI POPULATION DISTRIBUTION

Macroscopic distribution of the Hui nationality throughout from Southeast to Northwest as irregular " $t$ " shape (as shown in Figure 1). In the country's 56 ethnic groups, so widely distributed, number of so many people, in addition to Han's only Hui. From the study of the Hui population, bulk rate, villages, townships, counties, prefectures and the autonomous communities are in direct response to the degree of separation and reunion of the significant parameters of the population of the Hui nationality in China. Due to the distribution of all autonomous regions, autonomous prefectures of the Hui nationality in the Northwest Territories, $47.2 \%$ of the total national population of Hui Hui population in Northwest China, indicating that was the first large Chinese Hui-inhabited area in the Northwest. Macroscopic distribution morphology of the Hui in China could use "scattered, small concentration" to describe housing patterns can be divided into a region, or mixed, the diaspora of three modes.

\section{HuI’s MODE OF REGIONS}

\section{A. Colony}

"Colony" is gathered to live. Only there is inhabited by the Hui nationality in the environment, "in terms of traditional culture and customs, save more complete, lifestyle changes play a diverting function [2]." Hui in China of live way performance for "town since into streets, in village since into village", Northwest of Hui more live, such as Ningxia Yongning County is satisfied that households village, to village for units live, also has few to Township, and town for units of live district, such as Yunnan province gejiu Sha meadow district, and Ningxia yinchuan suburb of tongguixiang, maximum of live units is County, such as Ningxia jingyuanxian (Hui population accounted for population total of $96 \%)$.

\section{B. Mix}

"Mix" is inhabited by two or more people gather in one place of residence, is a State of relative population of the Hui nationality and inhabited compared to overall distribution of the Hui nationality and inhabited by other peoples patterns. Also, whether it is in the village are of the Hui district, Township, County, usually mostly of other peoples to live in and around the village, village, town, flower arrangement, interlaced mixed mixed trend. 


\section{C. scatter}

"Scatter" is the geographical distribution of the Hui in China, generally from the Northwest to the East, South China, Southwest region-inhabited by-scattered laws [3]. Loss of national identity of the diaspora tends to be part of the Hui nationality, as scattered further away from Hui, national liaison between individuals, between individuals and groups weakening, customs, traditional activities specific to national participation gradually reduced, resulting in the loss of national culture resulting in the loss of Hui people's national identity

\section{HuI IN THE GROUP CONSCIOUSNESS PSYCHOLOGY}

\section{A. The Hui group consciousness}

Has a strong sense of group consciousness and cohesion of the Hui nationality, so in China "Moslems in the world are a" argument. The reason is, first, the role of kinship groups of the Hui nationality, "a majority of residents of the village have ties of kinship by blood or affinity" [4]; the second is the role of national psychological, the Hui has a high level of group cohesion. Hui Hui group consciousness of preservation of national psychological traits and very strongly the inextricable relationship, group consciousness of their peoples in the course of its development remains populated by ethnic inseparable for a long time. Manner only through a inhabited for the common life of the Hui nationality customs, religion, nation, national character, national spirit and get the maximum inheritance and protection. Is different from the other peoples of the mental characteristics of the Hui nationality will be continued consolidation and development to the maximum extent.

\section{B. Colonies are Hui people's material and spiritual life needs}

Since the beginning of mankind is the way to live. Lower production levels of agricultural societies, social needs of not only the material aspects of more psychological sense of security needs, just as Fei Xiaotong said: "from the agriculture itself, many people live together without rural inhabited communities of different sizes, out of agriculture for reasons other than their own. Not least because of the agricultural community to form villages, villages provides villagers with a security guarantee to meet the domestic and social needs of the villagers. "[5]" he has meetings and partings reflects the relationship between man and man, population concentration is to decide for one or together for larger groups in the economic life of the community "[6]. Agricultural production in the era of teamwork among the groups of activities cannot be separated from, and the same ethnic groups of total farming cooperation more efficient. At the same time, individuals live in groups, an important reason why groups are strong individuals, with the power groups can protect the interests of individuals, so as to safeguard the interests of the group as a whole. Hui is the main reason and safeguarding the common interests of the economic life.
Hui is not original clan, the original tribal fusion development in ancient China and the formation of national, and largely came from historical records to become "foreign guests" part of the Arabs, the Persians over time and the integration of $\mathrm{Li}$ and Han nationalities. Records containing "remain in Chang-Hu ... ... Tenure does not wish to return "," no one wishes to all "[7]," and it's time, has to stay don't go "[8]. As a guest from Afar "foreign guests" because of the common faith, a common cultural background, as well as a common language and common life of geographical and natural environment make these common "characteristics" to stable development. As Li Peilun says: "every social group, the creators for their common culture. Casting common psychological quality of common culture and common way of life, which allow social groups to maintain unity and stability, "[9]. Inheritance of traditional culture also contributed to the Hui. Hui people from birth to death, has a series of life etiquette and customs, a Muslim life is indispensable. This combination of etiquette could be achieved only through collective environment, thus from generation to generation.

\section{Hui People's Sense of Belonging AND "Hui Fang"}

\section{A. Hui people's sense of belonging}

A sense of belonging, or sense of membership, membership, there are two meanings: (1) individual consciousness is recognized and accepted by other people or groups feeling when; (2) is Fromm (E.Fromm) 's theory of terms, meaning the sense of psychological sense of security and the implementation.Reassign number of columns: Place your cursor to the right of the last character of the last affiliation line of an even numbered affiliation (e.g., if there are five affiliations, place your cursor at end of fourth affiliation). Drag the cursor up to highlight all of the above author and affiliation lines. Go to Column icon and select "2 Columns". If you have an odd number of affiliations, the final affiliation will be centered on the page; all previous will be in two columns.

"As certain cultural communities,each closely tied to the body of a nation with its own environment" [10]. In the Northwest Territories, all the Chinese Muslims have the same religion, the same values and are subject to the same norms of conduct naturally have the same standards of moral evaluation. Is this common beliefs, values and behavioral norms formed the basis of the social order, maintaining contact between members, the individual then has a strong sense of belonging.

\section{B. Hui Fang's elements and functions}

"Square" concept comes from the Tang and Song dynasties "fan corner", is the collective consciousness of the Hui nationality and housing patterns the most direct material carrier, it is a group of common cultural characteristics, the same values of life and common psychological quality and mutual obligations of the Hui nationality ancestors ' individuals gather in living together, living together, production of a particular region of space. "Hui" elements are (1) based on certain social relations organize groups live in certain geographic and space; a certain kinship of Hui (early settlers), geographical (immigration movement) or a karmic 
relationship (demand) as a link and the Foundation is organizing, living in a range of geographical space. (2) share common beliefs, cultures, social norms of behaviour and ways of life; have a common belief-Hui-Islam is the most distinctive feature, guided by the belief, the Hui customs, habits, culture and norms of social behaviour and even lifestyle, production has been affected by the profound influence of Islam. Scholars Ma Zongbao from a sociological point of view, "square" is a typical community of the Hui community, is a unique cultural landscape of the Chinese society ...... [11] from the "square" elements is not difficult to get "back corner" feature: (1) gathered individuals of the Hui nationality, perfect groups of the Hui nationality, and (2) custom of Hui people in Islamic culture, heritage, and (3) normative social behavior of individuals, groups and lifestyles.

\section{C. "HUI FANG" type and space [12]}

"Hui Fang" concept comes from the Tang and Song dynasties "fan corner", housing patterns is the collective consciousness of the Hui nationality with the most direct physical carrier, it is a group of common cultural characteristics, the same values of life, the common psychological quality and mutual obligations of the Hui nationality ancestors ' individuals gather in living together, living together, the production of a particular region of space. "Hui" elements are (1) based on certain social relations organize group activities within a certain geographical and space; a certain kinship of Hui (early settlers), geographical (immigration movement) or a karmic relationship (demand) as a link and the Foundation is organizing, living in a range of geographical locations. (2) share common beliefs, cultures, social behaviour and lifestyles; Hui, based on common belief Islam is the most distinctive feature, guided by the belief, the Hui customs, habits, culture and social behaviour, lifestyles, patterns of production are profoundly influenced by the Islam. Scholars Ma Zongbao from a sociological point of view, the "square" is a typical community of the Hui community, is a unique cultural landscape in Chinese society ... ... [11] from the "square" elements is not difficult to get "corner" feature: (1) gathered individuals of the Hui nationality, perfect groups of the Hui nationality, and (2) the heritage of Islamic culture and customs of the Hui nationality, and (3) normative social behavior of individuals, groups and lifestyles.

"Hui Fang" is the mosque-centric, the Hui individual "wall Temple", formed by buildings such as mosques and residential areas surrounding the settlement of space. Usually a "square" only one mosque, rarely has a "square" Temple. For example, Weizhou yihewani $60 \%, 10 \%$ per cent at the end of the old, they are dispersed in the Weizhou 11 mosques (which Su Jiasi, sea Temple, Temple), Weizhou Mosque is always square Temple. Small temple is a large temple leadership. Weizhou marriage, Funeral, Jumu'ah, Eid al-Fitr, Eid-Ul-Adha in the great temple. Ecological resettlement project, however due to move into the city, immigrants from different denominations, and in the process does not take into account the distribution of residential buildings from various "square" cause they have to build different concentrations of the same mosque for prayer, resulting in a "square" Temple.

\section{ACKNOWLEDGMENT}

\section{Fund Project:}

National Natural Science Foundation of China: (Grant No.: 51168040)

Key Technologies $\mathrm{R} \quad \& \mathrm{D}$ Program of Ningxia Province(Grant No.: 2012ZYS159)

\section{REFERENCES}

[1] Ma Zongbao.On the Muslim community "Square"[J]. Social Sciences in Ningxia, 1994, 67 (5) : 16-22

[2] Ma Zhifu.Xinjiang Hui Muslim lifestyle change research community[J]. Hui Studies, 1995,(4)

[3] Ma Ping. Hui psychological and behavior[M]. Yinchuan: Ningxia People's Publishing House, 1998 : 2

[4] U.S.) F • PuLuoge, D • G • Bates.Cultural Evolution and Human Behavior[M]. WU Ai-ming, DENG Yong Shenyang: Liaoning People's Publishing House, 1988 : 179

[5] Anthropology and Folklore Research Communications, pp. 28-29 period

[6] Fei Xiaotong. Reproductive system [M]. Tianjin: Tianjin People's Publishing House, 1981:79

[7] Comprehensive Mirror, Volume 232

[8] Jinji Tang. History of Islam in China [M]. Beijing: Peking into the publishing division of Teachers, 1935

[9] Li Peilun.Green Meditation [M]. Taiyuan: Shanxi Ancient Books Publishing House, 1994:19

[10] (Soviet Union) Bo Luomu lei.Ethnic and Ethnology [M]. Lizhen Xi, Liu end. Hohhot: Inner Mongolia Press, 1985:40

[11] Ma Zongbao. On the Muslim community "Square" [J]. Social Sciences, 1994,67 (5) :16-22

[12] Ma Zongbao. On the Muslim community "Square" [J]. Social Sciences, 1994,67 (5) :16-22 